\title{
Molecular detection of Toxoplasma gondii in aborted fetuses of goats in Chattogram, Bangladesh
}

\author{
Tanjila Hasan'1(D), Abdul Mannan²(i), Delower Hossain ${ }^{3}$ (D), Azizunnesa Rekha1(D), Md. Monir Hossan ${ }^{4}$, \\ Mohammad Abdul Alim ${ }^{5}$ iD and AHM Musleh Uddin ${ }^{6}$ (i)
}

\begin{abstract}
1. Department of Medicine and Surgery, Faculty of Veterinary Medicine, Chattogram Veterinary and Animal Sciences University, Chattogram 4225, Bangladesh; 2. Teaching and Training Pet Hospital and Research Center, Chattogram Veterinary and Animal Sciences University, Chattogram 4225, Bangladesh; 3. Department of Medicine and Public Health, Faculty of Animal Science and Veterinary Medicine, Sher-e-Bangla Agricultural University, Dhaka 1207, Bangladesh; 4. Upazila Livestock Office, Department of Livestock Services, Farmgate, Dhaka 1215, Bangladesh; 5. Department of Pathology and Parasitology, Faculty of Veterinary Medicine, Chattogram Veterinary and Animal Sciences University, Chattogram 4225, Bangladesh; 6. Department of Surgery and Theriogenology, Faculty of Veterinary, Animal and Biomedical Sciences, Sylhet Agricultural University, Sylhet 3100, Bangladesh. Corresponding author: AHM Musleh Uddin, e-mail: musleh.dst@sau.ac.bd

Co-authors: TH: tanjila@cvasu.ac.bd, AM: mannanhasmi_2008@yahoo.com,DH: delowervet@sau.edu.bd, AR: azizunnesa@cvasu.ac.bd, MMH: monir_cvasu@yahoo.com, MAA: mdabdul.alim@my.jcu.edu.au

Received: 25-02-2021, Accepted: 02-08-2021, Published online: 14-09-2021
\end{abstract}

doi: www.doi.org/10.14202/vetworld.2021.2386-2391 How to cite this article: Hasan T, Mannan A, Hossain D, Rekha A, Hossan MM, Alim MA, Uddin AHMM (2021) Molecular detection of Toxoplasma gondii in aborted fetuses of goats in Chattogram, Bangladesh, Veterinary World, 14(9): 2386-2391.

\begin{abstract}
Background and Aim: Toxoplasma gondii is a protozoan parasite that is responsible for the major cause of congenital diseases, abortion, and stillbirth in humans and farm animals. Primary infection in pregnant goats due to T. gondii leads to abortion and significant economic losses in the livestock industry. Moreover, very few studies have been performed for the identification of T. gondii from aborted fetuses of goats. The study was conducted for the molecular identification of Toxoplasma gondii from aborted fetuses of goats in Chattogram, Bangladesh.
\end{abstract}

Materials and Methods: Twenty aborted fetuses of goats were collected from 52 farms in the study area. A nested polymerase chain reaction (PCR) assay targeting the B1 gene was performed, and a positive sample yield of 197 bp amplified DNA products consistent with T. gondii.

Results: The overall prevalence of toxoplasmosis in the aborted fetus of goats was $35 \%$. Heart muscle, liver, brain, and placenta showed positive PCR results. The risk factors related to the does age, presence of cats in farms, and aborted fetus age were found to be statistically significant $(\mathrm{p}<0.05)$. Our results showed that $T$. gondii is a major possible causal factor for abortion and reproductive failure in goats. The high prevalence of $T$. gondii infection in aborted fetuses of goats revealed that $T$. gondii could be imperative in causing reproductive failure in goats.

Conclusion: Active or congenital toxoplasmosis was shown by the presence of $T$. gondii in fetal tissues, which is a matter of concern as this parasite has zoonotic significance and causes economic hazards to the livestock industry by causing various reproductive problems. Therefore, proper control measures and strategies are needed to reduce the rate of abortion in goats, ultimately saving the livestock industry.

Keywords: aborted fetus, goat, nested polymerase chain reaction, Toxoplasma gondii.

\section{Introduction}

Toxoplasma gondii, an obligate intracellular protozoan parasite with noteworthy zoonotic importance, causes toxoplasmosis in humans and warm-blooded animals [1]. Consumption of raw or uncooked meat and fish containing bradyzoites (water, milk, and vegetables contaminated with oocysts) and transfusion and transplantation of blood and organs, respectively, harboring tachyzoites from patients infected with T. gondii are the major sources of T. gondii infection

Copyright: Hasan, et al. Open Access. This article is distributed under the terms of the Creative Commons Attribution 4.0 International License (http://creativecommons.org/licenses/by/4.0/), which permits unrestricted use, distribution, and reproduction in any medium, provided you give appropriate credit to the original author(s) and the source, provide a link to the Creative Commons license, and indicate if changes were made. The Creative Commons Public Domain Dedication waiver (http://creativecommons.org/ publicdomain/zero/1.0/) applies to the data made available in this article, unless otherwise stated. in humans [2]. As a final host, cats play an important role in spreading T. gondii infection [3]. Therefore, poor hygienic management of farms, climate, presence of cats in farms, consuming raw or uncooked meat and vegetables, and inter-current diseases may act as potential risk factors influencing this disease [4].

Toxoplasmosis is an economically indispensable disease of farm animals, especially goats and sheep [5]. At present, it is considered as a major cause of abortion in goats worldwide [6,7]. The sexual life cycle of $T$. gondii is restricted to cats; however, the asexual cycle depends on humans and other intermediate hosts [8]. Goats are infected by ingesting oocysts excreted through cat feces in the environment and congenital transmission through the placenta. Recently, scientists have reported that tachyzoites might pass over the placenta and infiltrate into the fetus with various consequences, depending on the stage of pregnancy $[9,10]$. Toxoplasmosis in goats 
causes early embryonic and fetal death, mummification, abortion, stillbirth, and neonatal death [11]. It is also subsequently associated with calcification and necrosis of the fetal cotyledons and normal intercotyledonary areas [12].

Nowadays, polymerase chain reaction (PCR) amplification of different genes to detect the $T$. gondii from aborted samples is a valuable and reliable technique [6]. A few studies were conducted in Bangladesh on the molecular detection of $T$. gondii in goats and sheep [13]. However, despite the high economic return from goat farming, this enterprise faces several problems on which toxoplasmosis is crucial [14].

Although toxoplasmosis has a huge impact on the health of goats and humans, it was not properly studied in Bangladesh, especially in the Chattogram area. Thus, our study aimed to detect $T$. gondii infection molecularly by nested PCR from aborted goat fetuses in Chattogram, Bangladesh.

\section{Materials and Methods}

\section{Ethical approval and Informed consent}

This study was approved by the department of Medicine and Surgery, Faculty of Veterinary Medicine, Chattogram Veterinary and Animal Sciences University, Chattogram. Moreover, before sample collection, consent from goats' owner was taken properly.

\section{Study period and farm selection}

A cross-sectional study was conducted from January 2019 to December 2019. Goats of smallholder farms under Chattogram metropolitan area were considered as the reference population. A farm having at least five goats along with the history of abortion was treated as the source population. A total of 52 farms were chosen conveniently representing different surrounding areas of Chattogram metropolitan area. Goats more than 6 months of age beyond selected farms were considered for sample collection. A total of 20 aborted goat fetuses were collected for molecular detection.

\section{Collection of aborted fetus samples}

Eighty seven samples were collected, including heart muscle (20), liver (20), lung (20), brain (20), and placenta (7) from the 20 aborted fetuses of goat. All samples collected were preserved at $-20^{\circ} \mathrm{C}$ until molecular examination.

\section{Questionnaire survey}

A closed-ended questionnaire was used to collect farm demography, farm management, and owners' information. The questionnaire also included information regarding aborted fetuses and goats, such as age, gestational age, body condition, and presence of cats in and around farm areas. The age of the animal was determined based on dentition and farmers' information.

\section{DNA extraction from tissue samples}

Genomic DNA extraction from tissue samples (heart, liver, lung, brain, and placenta) was performed using a commercial DNA extraction kit (Favorgen, Favorgen Biotech Corp, Taiwan) following the manufacturer's protocol. Briefly, $25 \mathrm{mg}$ tissue sample was taken into a sterilized mortar and pestle and ground to make a homogenous mixture using phosphate buffered serum. After centrifugation, cells were lysed and digested with $20 \mu \mathrm{L}$ proteinase $\mathrm{K}(10 \mathrm{mg} / \mathrm{mL}), 4 \mu \mathrm{L}$ RNase A (100 mg/mL), and $200 \mu \mathrm{L}$ FATG1 lysis/ binding buffer at $70^{\circ} \mathrm{C}$ for $10 \mathrm{~min}$. Then, $200 \mu \mathrm{L}$ ethanol $(96 \% \sim 100 \%)$ was added, and the mixture was transferred and placed in the FATG Mini column in a $2 \mathrm{~mL}$ collection tube and centrifuged at $14,000 \mathrm{rpm}$ for $1 \mathrm{~min}$. Next, the FATG columns were washed twice with washing buffer by centrifugation for $1 \mathrm{~min}$. After, the DNA was eluted from the columns by adding $50 \mu \mathrm{L}$ elution buffer to the membrane center of the FATG column and stored at $-20^{\circ} \mathrm{C}$.

\section{Target genes}

The multi-copy B1 gene 197 bp was the PCR target gene evaluated in this study [15]. The B1 gene consists of 35 copies, and it has high sensitivity and specificity among different $T$. gondii strains [15-17]. Primers used for identification of B1 gene: Specific primers were selected according to Wiengcharoen et al. [15] for primary and secondary PCR to amplify a portion of the B1 gene and identify the B1 gene (Table-1).

\section{B1 gene amplification by nested PCR and run gel}

Nested PCR was performed using a 2720 thermal cycler (Applied Biosystem, USA) in a total reaction volume of $25 \mu \mathrm{L}$ containing $12.5 \mu \mathrm{L}$ GoTaq G2 Hot Start Green Master Mix $(2 \times$ Green GoTaq Reaction Buffer, pH 8.5, $400 \mu \mathrm{M}$ dATP, $400 \mu \mathrm{M}$ dGTP, $400 \mu \mathrm{M}$ dCTP, $400 \mu \mathrm{M}$ dTTP, and $4 \mathrm{mM} \mathrm{MgCl}$ ), $1.5 \mu \mathrm{L}$ of each primer (10 picomoles) derived from $\mathrm{B} 1$ gene, 2 $\mu$ L of the template (sample DNA), and $7.5 \mu$ L nuclease free water. For PCR amplification, initial denaturation was performed at $94^{\circ} \mathrm{C}$ for $30 \mathrm{~s}$, followed by 35 cycles of denaturation at $94^{\circ} \mathrm{C}$ for $15 \mathrm{~s}$, annealing at $45^{\circ} \mathrm{C}$ for $30 \mathrm{~s}$, extension at $72^{\circ} \mathrm{C}$ for $45 \mathrm{~s}$, and final extension at $72^{\circ} \mathrm{C}$ for $10 \mathrm{~min}$. PCR reaction was performed at a temperature similar to the primary PCR for the nested PCR, but the amplification cycles were conducted for 35 cycles. The PCR amplified products were visualized by electrophoresis on agarose gel 1.5\% stained with ethidium bromide. Furthermore, the size of DNA fragments was visualized based on a 100 bp DNA ladder under ultraviolet transillumination. The images were captured using a camera.

\section{Statistical analysis}

Data were analyzed using SPSS v.22.0. The normality test of data was performed by the KolmogorovSmirnov test [18]. Chi-square test was performed to assess the risk factors [19]. Results were considered significant when $\mathrm{p}<0.05[20]$.

\section{Results}

Twenty aborted fetuses of goats were selected for molecular detection of $T$. gondii by nested PCR. Seven 
fetuses were positive for the T. gondii B1 gene (197 bp) (Figure-1). Our findings revealed that the prevalence of T. gondii was $35 \%$ in aborted fetuses from goats (Table2). Here, Figure-1 showed the sizes of the PCR product and distribution of positive cases among different tissue samples from aborted fetuses of goats.

In this study, 87 tissue samples were tested for T. gondii B1 gene detection (Table-3). Seven tissue

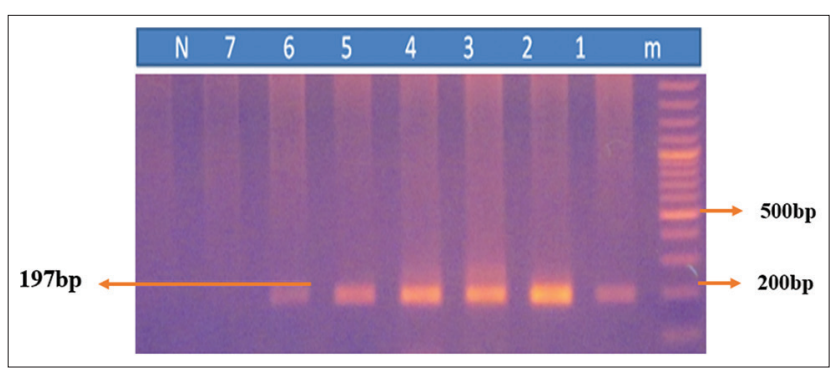

Figure-1: Polymerase chain reaction products amplified using B1 gene. Lane M: 100 bp DNA ladder (Invitrogen), lane N: Negative control, lane 1, 2, 3, 4, 5, and 6: Positive 7 and 8; negative samples. samples were positive for T. gondii (8.1\%) (Table-4). Interestingly, heart muscle, liver, brain, and placenta showed positive results in nested PCR. In contrast, lung samples revealed negative results in this study. The positive results were higher in the brain and placenta, followed by the heart muscle. Moreover, the least negative results were found in the lung compared with liver samples.

Age of does, presence of cats in and around farm premises, and age of aborted fetus were found to be statistically significant $(\mathrm{p}<0.05)$ variables for the presence of $T$. gondii in aborted fetuses of goats in the Chi-square test (Table-5). The prevalence of $T$. gondii was significantly $(\mathrm{p}<0.05)$ higher in does aged $2-3$ years compared to $>3$ years. In addition, the presence of cats in and around farms showed a significantly higher $(p<0.05)$ percentage than the absence of cats. However, aborted fetus age was higher in more than 3.5 months compared to $<3.5$ months; the difference was statistically significant $(\mathrm{p}<0.05)$.

Table-1: Selected primer to amplify a portion of B1 gene for the identification of Toxoplasma gondii.

\begin{tabular}{lllcc}
\hline Target gene & Primer name & Sequence & Amplification size (bp) & Reference \\
\hline B1 (primary) & Toxo-F1 & 5' -TCA AGC AGC GTA TTG TCG AG-3' & - & [15] \\
& Toxo-R1 & 5'-CCG CAG CGA CTT CTA TCT CT-3' & \\
B1 (secondary) & Toxo-F2 & 5'-GGA ACT GCA TCCGTT CAT GAG-3' & 197 bp \\
& Toxo-R2 & 5'-TCT TTA AAG CGTTCG TGG TC-3' & & \\
\hline
\end{tabular}

Table-2: Toxoplasma gondii in aborted fetus of goat based on nested PCR.

\begin{tabular}{lcccc}
\hline Total no. of fetus & \multicolumn{2}{c}{ Toxoplasma gondii nested PCR } & Prevalence (\%) \\
\cline { 2 - 4 } & Positive fetus & Negative fetus & \\
\hline 20 & 7 & 13 & 35.00 \\
\hline
\end{tabular}

$\mathrm{PCR}=$ Polymerase chain reaction

Table-3: Toxoplasma gondii in different tissue samples based on PCR assay.

\begin{tabular}{|c|c|c|c|c|c|c|}
\hline \multirow[t]{2}{*}{ Fetuses } & \multicolumn{6}{|c|}{ PCR results in different tissue samples } \\
\hline & Sample no. & Heart muscle & Liver & Lung & Brain & Placenta \\
\hline Fetus 1 & 5 & + & - & - & - & - \\
\hline Fetus 2 & 4 & - & - & - & - & NA \\
\hline Fetus 3 & 4 & - & - & - & - & NA \\
\hline Fetus 4 & 4 & + & - & - & - & NA \\
\hline Fetus 5 & 5 & - & - & - & - & - \\
\hline Fetus 6 & 4 & - & - & - & - & NA \\
\hline Fetus 7 & 5 & - & - & - & + & - \\
\hline Fetus 8 & 4 & - & - & - & + & NA \\
\hline Fetus 9 & 4 & - & - & - & - & NA \\
\hline Fetus 10 & 4 & - & - & - & - & NA \\
\hline Fetus 11 & 5 & - & - & - & - & + \\
\hline Fetus 12 & 5 & - & - & - & - & - \\
\hline Fetus 13 & 4 & - & - & - & - & NA \\
\hline Fetus 14 & 4 & - & - & - & - & NA \\
\hline Fetus 15 & 4 & - & - & - & - & NA \\
\hline Fetus 16 & 4 & - & - & - & - & NA \\
\hline Fetus 17 & 4 & - & - & - & - & NA \\
\hline Fetus 18 & 5 & - & - & - & + & - \\
\hline Fetus 19 & 5 & - & - & - & - & - \\
\hline Fetus 20 & 4 & - & + & - & - & NA \\
\hline Total sample & 87 & 20 & 20 & 20 & 20 & 7 \\
\hline
\end{tabular}

$\mathrm{NA}=$ Tissue not available, $\mathrm{PCR}=$ Polymerase chain reaction 


\section{Discussion}

In our study, the prevalence of $T$. gondii infection in aborted fetuses of goats is $35 \%$. Our findings were similar to that of Unzaga et al. [12], who confirmed $36 \%$ prevalence in aborted goat fetuses. Similar results were recorded by Pereira-Bueno et al. [21], who found 37 out of 106 analyzed fetuses with a prevalence of $34.9 \%$. The prevalence of this study was slightly higher compared with the results of $26.8 \%$ from Ghana [22], 27\% from Iran [11], and $27.1 \%$ from Thailand [23]. Our results are sharply lower than the findings of Chaechi Nosrati et al. [10], who showed that the prevalence of $T$. gondii infection was $68.18 \%$ based on the molecular nested PCR method [10]. Abu-Dalbouh et al. [6] reported that the overall prevalence (\%) of $T$. gondii was $41.8 \%$ for aborted goats from Jordan. The variation in prevalence is due to variations in health management, feeding and watering systems, nutrition regimens for pregnant animals, biosecurity systems, geographical locations, season, weather, carrier intensification, parasitic genomic diversity, and genetic marker polymorphisms significantly influence the percentage of abortion $[24,25]$.

Several researchers have reported that the brain sample is one of the most susceptible tissues to $T$. gondii infection due to the formation of cysts in the brain [10,21,26,27]. Our results are slightly higher than the findings of Partoandazanpoor et al. [11], who detected $8.1 \%$ from brain samples. Chaechi Nosrati et al. [10] illustrated that $T$. gondii infection

Table-4: Presence of Toxoplasma gondii in different tissue samples from aborted fetus of goats based on nested PCR.

\begin{tabular}{lccc}
\hline $\begin{array}{l}\text { Tissue } \\
\text { sample }\end{array}$ & \multicolumn{2}{c}{$\begin{array}{c}\text { Toxoplasma gondii } \\
\text { Nested PCR }\end{array}$} & Percentage \\
\cline { 2 - 3 } & $\begin{array}{c}\text { Tested } \\
\text { sample }\end{array}$ & $\begin{array}{c}\text { Positive } \\
\text { sample }\end{array}$ & \\
\hline Heart muscle & 20 & 2 & 10.0 \\
Liver & 20 & 1 & 5.0 \\
Lung & 20 & 0 & 0 \\
Brain & 20 & 3 & 15.0 \\
Placenta & 7 & 1 & 14.3 \\
Total & 87 & 7 & 8.1 \\
\hline
\end{tabular}

$\mathrm{PCR}=$ Polymerase chain reaction was identified in $68.20 \%$ of brain tissue samples from aborted ovine fetuses, which is considerably higher than our result. It was observed that fetal brain tissue and placental samples were considered vital tools for diagnosing congenital toxoplasmosis by detecting different $T$. gondii genes by PCR [21].

Risk factors, such as doe age, presence of cats in and around farms, and gestation period influence the prevalence of $T$. gondii in goats [28-30]. There is a significant statistical $(p<0.05)$ difference between prevalence and doe age in this study, and this agrees with the findings of several studies that reported that young animals are more vulnerable to $T$. gondii infections than older animals [31-34]. This may indicate the dominance of maternally acquired antibodies in the early stage of goats, unless re-infected, lessening antibodies as their age rises [29]. Our findings disagreed with that of Saeed et al. [30], who reported that older animals are more susceptible than young animals to T. gondii infection due to continuous exposure to risk factors for a longer period in older animals.

Our findings revealed a significant relationship between $T$. gondii infections with the presence of cats in farm premises. Recent studies have observed that direct or indirect contact of cats is a prominent risk factor for toxoplasmosis in goats $[28,30,35]$. Cats are considered a definitive part of the life cycle of $T$. gondii and excrete oocytes of $T$. gondii in their feces, which contaminate water and feed sources and materials. Therefore, there is a high chance of getting infected from contaminated feed and water [30]. Researchers also reported that using surface water sources, including lakes and rivers, as drinking water for animals might be a risk factor for $T$. gondii infections as cats pass out their feces in their (lakes and rivers) contiguity [28].

The frequency of $T$. gondii infection also depends on the age of the aborted fetus. Our findings are similar to those of several studies [5,6,36,37]. The gestation period and immune status of fetuses correlate with the exposure of toxoplasmosis during pregnancy. In early gestational infections, fetal death occurred due to the immature immune system of fetuses [5]. The most common outcome is stillborn during mid-gestational infections, whereas late gestational infections accounted for abortions, stillbirth, or normal offspring [37].

Table-5: Distribution of categorical variables among Toxoplasma gondii positive aborted fetus of goat.

\begin{tabular}{|c|c|c|c|c|c|c|}
\hline Variable & Number sampled & Test positive & Prevalence (\%) & $d f$ & $\chi^{2}$ & p-value \\
\hline \multicolumn{7}{|l|}{ Doe age } \\
\hline $2-3$ years & 13 & 5 & 38.46 & 1 & 13.77 & $p<0.05$ \\
\hline$>3$ years & 7 & 2 & 28.57 & & & \\
\hline \multicolumn{7}{|l|}{ Presence of cat } \\
\hline Yes & 8 & 5 & 62.50 & 1 & 8.63 & $p<0.05$ \\
\hline No & 12 & 2 & 16.67 & & & \\
\hline \multicolumn{7}{|c|}{ Aborted fetus age } \\
\hline$<3.5$ months & 6 & 1 & 16.67 & 1 & 7.21 & $p<0.05$ \\
\hline$>3.5$ months & 12 & 6 & 50.00 & & & \\
\hline
\end{tabular}

Here, $d f$-Degree of freedom, $\chi^{2}$-Chi-square 


\section{Conclusion}

Our current report on the molecular detection of $T$. gondii infection in goats in Chattogram district, Bangladesh, estimating a higher prevalence. In addition, doe age, presence of cats in farms, and aborted fetus age showed an association with the infection. Our findings will increase the awareness among veterinarians, researchers, and farmers about the epidemiology and distribution of $T$. gondii infection in this region. Further studies are needed to explore more information regarding different genotypes of $T$. gondii and their association with abortion and other reproductive complications in the goat population.

\section{Authors' Contribution}

TH, AM, and AR: Study design. TH, MMH, and MAA: Performed laboratory experiments. TH, $\mathrm{DH}$, and AHMMU: Drafted the manuscript. AM and MAA: Reviewed and edited the manuscript. All authors read and approved the final manuscript.

\section{Acknowledgments}

The authors are thankful to the authority of Poultry Research and Training Centre, Chattogram Veterinary and Animal Sciences University, Chattogram, Bangladesh, for providing the necessary support during the study. We would like to convey our deepest gratitude to National Science and Technology (NST), Bangladesh, for funding the project (Grant no. BS-183/187).

\section{Competing Interests} interests.

The authors declare that they have no competing

\section{Publisher's Note}

Veterinary World remains neutral with regard to jurisdictional claims in published institutional affiliation.

\section{References}

1. Ybañez, R.H.D., Ybañez, A.P. and Nishikawa, Y. (2020) Review on the current trends of toxoplasmosis serodiagnosis in humans. Front. Cell. Infect. Microbiol., 10(204): 1-8.

2. Kolören, Z. and Dubey, J.P. (2020) A review of toxoplasmosis in humans and animals in Turkey. Parasitology, 147(1): 12-28.

3. Dubey, J.P. (2009) Toxoplasmosis of Animals and Humans. CRC Press, United States.

4. Ferra, B., Holec-Gasior, L. and Graźlewska, W. (2020) Toxoplasma gondii recombinant antigens in the serodiagnosis of toxoplasmosis in domestic and farm animals. Animals, 10(8): 1-27.

5. Stelzer, S., Basso, W., Silván, J.B., Ortega-Mora, L.M., Maksimov, P., Gethmann, J., Conraths, F.J. and Schares, G. (2019) Toxoplasma gondii infection and toxoplasmosis in farm animals: Risk factors and economic impact. Food Waterborne Parasitol., 15: e00037.

6. Abu-Dalbouh, M.A., Ababneh, M.M., Giadinis, N.D. and Lafi, S.Q. (2012) Ovine and caprine toxoplasmosis (Toxoplasma gondii) in aborted animals in Jordanian goat and sheep flocks. Trop. Anim. Health Prod., 44(1): 49-54.

7. Nayeri, T., Sarvi, S., Moosazadeh, M. and Daryani, A.
(2021) Global prevalence of Toxoplasma gondii infection in the aborted fetuses and ruminants that had an abortion: A systematic review and meta-analysis. Vet. Parasitol., 290: e109370.

8. Dubey, J.P., Pena, H.F.J., Cerqueira-Cézar, C.K., Murata, F.H.A., Kwok, O.C.H., Yang, Y.R., Gennari, S.M. and Su, C. (2020) Epidemiologic significance of Toxoplasma gondii infections in chickens (Gallus domesticus): The past decade. Parasitology, 147(12): 1263-1289.

9. Robert-Gangneux, F. and Dardé, M.L. (2012) Epidemiology of and diagnostic strategies for toxoplasmosis. Clin. Microbiol. Rev., 25(2): 264-296.

10. Chaechi Nosrati, M.R., Shemshadi, B., Shayan, P., Ranjbar Bahadori, S. and Eslami, A. (2020) High prevalence of Toxoplasma gondii infection in ovine aborted fetuses in Gilan Province, Iran: Molecular detection and genotype characterization. J. Basic Res. Med. Sci., 7(4): 53-62.

11. Partoandazanpoor, A., Sadeghi-Dehkordi, Z., Ekradi, L., Khordadmehr, M., Rassouli, M. and Sazmand, A. (2020) Molecular diagnosis and pathological study of Toxoplasma gondii in aborted caprine and ovine fetuses in borderline of Iran-Iraq. Acta Parasitol., 65(1): 187-192.

12. Unzaga, J.M., Moré, G., Bacigalupe, D., Rambeaud, M., Pardini, L., Dellarupe, A., De Felice, L., Gos, M.L. and Venturini, M.C. (2014) Toxoplasma gondii and Neospora caninum infections in goat abortions from Argentina. Parasitol. Int., 63(6): 865-867.

13. Sah, R.P., Dey, A.R., Rahman, A.K.M., Alam, M.Z. and Talukder, M.H. (2019) Molecular detection of Toxoplasma gondii from aborted fetuses of sheep, goats and cattle in Bangladesh. Vet. Parasitol. Reg. Stud. Reports., 18: e100347.

14. Chiang, S.H., Huang, H.H., Chou, C.C., Chu, C.S., Shih, W.L., Lai, J.M., Lin, H.C., Yang, W.C., Lee, H.H. and Tsai, Y.L. (2020) Epidemiological survey of Toxoplasma gondii and Neospora caninum infections in dairy goats in CentralSouthern Taiwan. J. Vet. Med. Sci., 82(10): 1537-1544.

15. Wiengcharoen, J.T., Chiabchalard, R. and Sukthana, Y. (2004) PCR technique for detecting Toxoplasma gondii in animal amniotic fluid. Southeast Asian J. Trop. Med. Public Health, 35(4): 792-795.

16. Contini, C., Cultrera, R., Seraceni, S., Segala, D., Romani, R., Fainardi, E., Cinque, P., Lazzarin, A. and Delia, S. (2002) The role of stage-specific oligonucleotide primers in providing effective laboratory support for the molecular diagnosis of reactivated Toxoplasma gondii encephalitis in patients with AIDS. J. Med. Microbiol., 51(10): 879-890

17. Sardarian, K., Maghsood, A.H., Farimani, M., Hajiloii, M., Saidijam, M., Rezaeepoor, M., Mahaki, H. and Zamani, A. (2018) Evaluation of Toxoplasma gondii B1 gene in placental tissues of pregnant women with acute toxoplasmosis. Adv. Biomed. Res., 7: 119.

18. Steinskog, D.J., Tjøstheim, D.B. and Kvamstø, N.G. (2007) A cautionary note on the use of the Kolmogorov--Smirnov test for normality. Mon. Weather Rev., 135(3): 1151-1157.

19. Camilli, G. and Hopkins, K.D. (1978) Applicability of chisquare to $2 \times 2$ contingency tables with small expected cell frequencies. Psychol. Bull., 85(1): 163

20. Rice, W.R. (1989) Analyzing tables of statistical tests. Evolution, 43(1): 223-225.

21. Pereira-Bueno, J., Quintanilla-Gozalo, A., Pérez-Pérez, V., Alvarez-Garcia, G., Collantes-Fernández, E., and OrtegaMora, L.M. (2004) Evaluation of ovine abortion associated with Toxoplasma gondii in Spain by different diagnostic techniques. Vet. Parasitol., 121(1-2): 33-43.

22. Van Der Puije, W.N.A., Bosompem, K.M., Canacoo, E.A., Wastling, J.M. and Akanmori, B.D. (2000) The prevalence of anti-Toxoplasma gondii antibodies in Ghanaian sheep and goats. Acta Trop., 76(1): 21-26.

23. Jittapalapong, S., Sangvaranond, A., Pinyopanuwat, N., Chimnoi, W., Khachaeram, W., Koizumi, S. and Maruyama, S. (2005) Seroprevalence of Toxoplasma gondii 
infection in domestic goats in Satun Province, Thailand. Vet. Parasitol., 127(1): 17-22.

24. Alemayehu, G., Mamo, G., Alemu, B., Desta, H., Tadesse, B., Benti, T., Bahiru, A., Yimana, M. and Wieland, B. (2021) Causes and flock level risk factors of sheep and goat abortion in three agroecology zones in Ethiopia. Front. Vet. Sci., 8: 27.

25. Arefkhah, N., Sarkari, B., Asgari, Q., Moshfe, A., Khalafi, M.H. and Mohammadpour, I. (2020) Molecular genotyping of Toxoplasma gondii in sheep aborted fetuses reveals predominance of Type I infection in Southwest of Iran. Iran. J. Parasitol., 15(3): 374-382.

26. Sreekumar, C., Rao, J.R., Mishra, A.K., Ray, D., Joshi, P. and Singh, R.K. (2004) Detection of toxoplasmosis in experimentally infected goats by PCR. Vet. Rec., 154(20): 632-635.

27. Dubey, J.P. (2009) Toxoplasmosis in pigs-the last 20 years. Vet. Parasitol., 164(2-4): 89-103.

28. Hotea, I., Herman, V., Tirziu, E., Colibar, O., Brudiu, I., Sirbu, C. and Duaruabuş, G. (2021) Seroprevalence and risk factors for Toxoplasma gondii infection in sheep and goats from Romania. Parasitologia., 1(2): 36-44.

29. Atail, H.B.M. (2017) Sero-prevalence of Toxoplasmosis in Sheep and Goats in El-Gadarif State, Doctoral Dissertation. Sudan University of Science \& Technology, Sudan.

30. Saeed, M.S., Randhawa, U.A., Ahmad, I., Ullah, M.I., Gul, S.T., Hassan, M.M., Ahmad, E. and Ijaz, N. (2021) Seroprevalence and risk factors of toxoplasmosis in Beetal goats in district Faislabad and its association with reproductive problems. Pakistan J. Agric. Sci., 58(2): 693-698.

31. Nematollahi, A. and Moghddam, G. (2008) Survey on seroprevalence of anti-Toxoplasma gondii antibodies in cattle in Tabriz (Iran) by IFAT. Am. J. Anim. Vet. Sci., 3(1): 121-126.

32. Elfahal, A.M., Elhassan, A.M., Hussien, M.O., Enan, K.A., Musa, A.B. and El Hussein, A.M. (2013) Seroprevalence of Toxoplasma gondii in dairy cattle with reproductive problems in Sudan. Int. Sch. Res. Not., 2013: 1-4.

33. Yin, M.Y., Wang, J.L., Huang, S.Y., Qin, S.Y., Zhou, D.H., Liu, G.X., Tan, Q.D. and Zhu, X.Q. (2015) Seroprevalence and risk factors of Toxoplasma gondii in Tibetan Sheep in Gansu province, Northwestern China. BMC Vet. Res., 11(1): 1-5.

34. Ahmad, N., Iqbal, Z., Mukhtar, M., Mushtaq, M., Khan, K.M. and Qayyum, M. (2015) Seroprevalence and associated risk factors of toxoplasmosis in sheep and goats in Pothwar region, Northern Punjab, Pakistan. Pak. J. Zool., 1(1): 161-167.

35. Rahimi, M.T., Daryani, A., Sarvi, S., Shokri, A., Ahmadpour, E., Mizani, A., Sharif, M. and Teshnizi, S.H. (2015) Cats and Toxoplasma gondii: A systematic review and meta-analysis in Iran. Onderstepoort J. Vet. Res., 82(1): 1-10.

36. Danehchin, L., Razmi, G. and Naghibi, A. (2017) Molecular detection of Toxoplasma gondii infection in aborted fetuses in sheep in Khorasan Razavi province, Iran. Iran. J. Vet. Med., 11(2): 147-154.

37. Salehi, M., Nezami, H. and Niazkar, H.R. (2020) Investigation of Toxoplasma gondii infection in aborted fetuses of sheep using PCR: A study in North Khorasan Province, Iran. Vet. Med. Int., 2020: 1-5. 